\title{
Nonintegrating Lentiviral Vector-Based Vaccine Efficiently Induces Functional and Persistent CD8+ T Cell Responses in Mice
}

\author{
Donatella R. M. Negri, ${ }^{1}$ Zuleika Michelini,, ${ }^{2}$ Silvia Baroncelli, ${ }^{2}$ Massimo Spada, ${ }^{3}$ \\ Silvia Vendetti, ${ }^{1}$ Roberta Bona, ${ }^{2}$ Pasqualina Leone, ${ }^{2}$ Mary E. Klotman, ${ }^{4}$ and Andrea Cara ${ }^{2}$ \\ ${ }^{1}$ Department of Infectious, Parasitic and Immune-Mediated Diseases, Istituto Superiore di Sanità, Viale Regina Elena 299, \\ 00161 Rome, Italy \\ ${ }^{2}$ Department of Therapeutic Research and Medicines Evaluation, Istituto Superiore di Sanità, Viale Regina Elena 299, \\ 00161 Rome, Italy \\ ${ }^{3}$ Department of Cell Biology and Neurosciences, Istituto Superiore di Sanità, Viale Regina Elena 299, 00161 Rome, Italy \\ ${ }^{4}$ Division of Infectious Diseases, Mount Sinai School of Medicine, 1 Gustave L. Levy Place, P.O. Box 1090, New York, \\ NY 10029, USA
}

Correspondence should be addressed to Donatella R. M. Negri, donatella.negri@iss.it and Andrea Cara, andrea.cara@iss.it

Received 14 December 2009; Revised 27 February 2010; Accepted 9 March 2010

Academic Editor: Kim Klonowski

Copyright ( $) 2010$ Donatella R. M. Negri et al. This is an open access article distributed under the Creative Commons Attribution License, which permits unrestricted use, distribution, and reproduction in any medium, provided the original work is properly cited.

\begin{abstract}
CD8+ $\mathrm{T}$ cells are an essential component of an effective host immune response to tumors and viral infections. Genetic immunization is particularly suitable for inducing CTL responses, because the encoded proteins enter the MHC class I processing pathway through either transgene expression or cross-presentation. In order to compare the efficiency and persistence of immune response induced by genetic vaccines, BALB/c mice were immunized either twice intramuscularly with DNA plasmid expressing a codon-optimized HIV-1 gp120 Envelope sequence together with murine GM-CSF sequence or with a single immunization using an integrase defective lentiviral vector (IDLV) expressing the same proteins. Results strongly indicated that the schedule based on IDLV vaccine was more efficient in inducing specific immune response, as evaluated three months after the last immunization by IFN $\gamma$ ELISPOT in both splenocytes and bone marrow- (BM-) derived cells, chromium release assay in splenocytes, and antibody detection in sera. In addition, IDLV immunization induced high frequency of polyfunctional CD8+ T cells able to simultaneously produce IFN $\gamma, \mathrm{TNF} \alpha$, and IL2.
\end{abstract}

\section{Introduction}

The importance of $\mathrm{CD} 8+\mathrm{T}$ cells in viral clearance has been established in several viral models [1], including the nonhuman primate model of AIDS, in which depletion of $\mathrm{CD} 8+\mathrm{T}$ cells resulted in the inability to clear infection $[2,3]$. Several other evidences demonstrated the importance of the CD8+ T cell responses for controlling HIV infection. Indeed, slow AIDS disease progression is associated with functional CD8+ T cell responses, specific HLA class I alleles are associated with slower progression of disease in HIVinfected people, and CTL escape is a major force driving HIV evolution (reviewed in $[4,5]$ ). Based on these findings, vaccines inducing strong and long-lived $\mathrm{CD} 8+\mathrm{T}$ cells are highly desirable. Genetic immunization using plasmid DNA or viral vectors is particularly suitable for inducing CTL responses, because the encoded protein enters the MHC class I processing pathway through either direct transgene expression or cross-presentation by resident antigen presenting cells (APCs). Among viral vectors, lentiviral vectors (LVs) have been shown to efficiently transduce non replicating cells in vitro as well as in vivo and to be able to elicit potent humoral and cellular responses (reviewed in [6]). LV-transduced human DCs are able to present antigenic peptides and prime transgene-specific T cells in vitro $[7,8]$. It has been shown that $\mathrm{LV}$-encoding HIV-1 polyepitopes induce broad CTL responses in mice [9], and we reported that a single intramuscular administration of HIV-based LVexpressing viral antigens elicits strong cell-mediated immune responses $[10,11]$. Importantly, Beignon and colleagues 

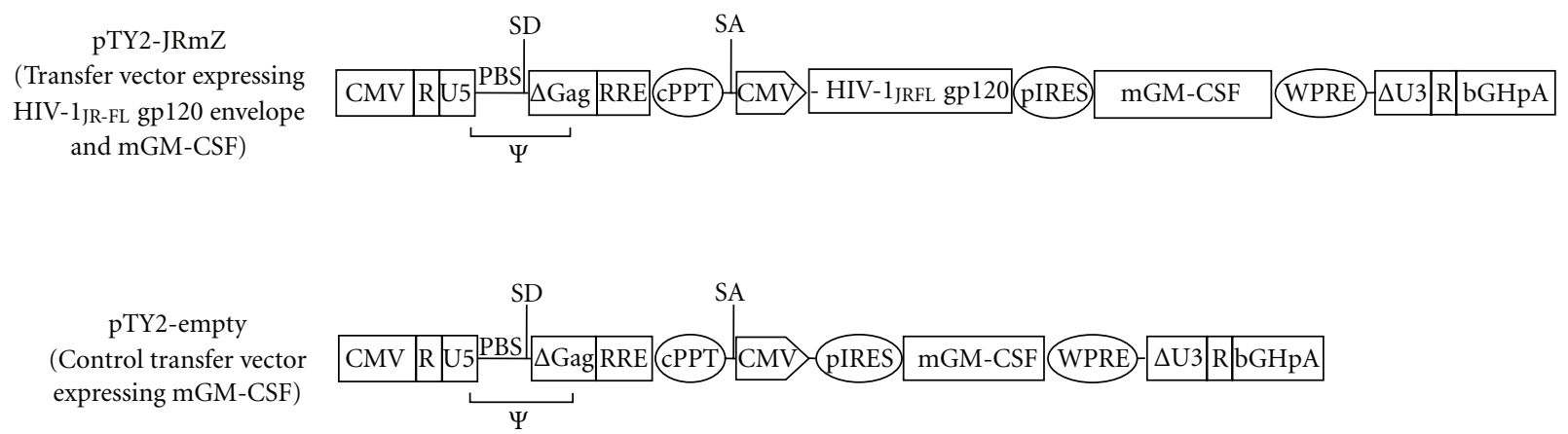

FIGURE 1: HIV-based transfer vectors plasmid used in this study. The internal CMV promoter drives the expression of the codon-optimized HIV $_{\text {IR-FL }}$ gp120 Envelope protein and the murine GM-CSF (mGM-CSF). The packaging signal ( $\Psi$ ), primer binding site (PBS), major splice donor (SD) and acceptor (SA) sites, bovine Growth Hormone polyadenylation signal (bHGpA), central polypurine tract (cPPT), internal ribosomal entry site from poliovirus (pIRES), and Woodchuck posttranscriptional regulatory element (WPRE) are indicated.

recently provided the first evidence that an LV-expressing simian immunodeficiency virus- (SIV-) Gag protein was able to induce control of viral replication in monkeys challenged with high dose of SIV [12]. However, safety concerns relative to the use of these vectors for delivery of therapeutic genes or for a vaccine include insertional mutagenesis and/or vector mobilization following viral infection. To minimize the risk of insertional mutagenesis, integrase defective lentiviral vectors (IDLV) have been engineered to present viral antigens in a similar but safer manner $[13,14]$. Several reports have shown that HIV- or SIV-derived integrase defective viruses as well as IDLV are transcriptionally active although at lower levels than the integrated wild-type counterpart, while producing extrachromosomal forms of viral DNA (E-DNA) in the absence of noticeable amounts of integrated provirus $[14,15]$.

We have recently demonstrated that a single immunization with a nonintegrating lentiviral vector carrying a codonoptimized HIV-1 gp120 Envelope protein in mice results in a strong and sustained immune response characterized by the presence of anti-gp120 antibodies, effector-specific T cells and generation of a specific $\mathrm{T}$ cell memory, without integration of the vector into the host genome [16]. Importantly, several groups confirmed the use of IDLV as an effective vaccine delivery strategy [17-19], and we provided evidence that SIV-based IDLV can be constructed and used as well [20].

In this work we compared the ability to induce longlasting CD8+ T cell response in mice upon immunization with DNA plasmid or IDLV expressing the HIV-1 gp120 Envelope protein. A detailed evaluation of CD8+ T cell immune response was performed at three months after the last immunization. Moreover, a comprehensive analysis of the quality of CD8+ $\mathrm{T}$ cell response induced by IDLV is reported.

\section{Materials and Methods}

2.1. Vectors Construction. A schematic depiction of the lentiviral transfer vector plasmids used in this study is shown in Figure 1. Details on vectors construction are provided in [16]. Briefly, the HIV-based transfer vector

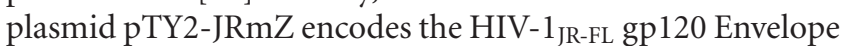
protein sequence (HIV-Env) and the murine granulocyte monocyte-colony stimulatory factor (mGM-CSF) from the internal CMV promoter; the HIV-based transfer control vector plasmid pTY2-EmptymZ encodes only the mGMCSF from the sequence for the poliovirus internal ribosomal entry site (pIRES). The Integrase (IN) defective packaging plasmid pcHelp/IN-, obtained from Dr. J. Reiser (Louisiana State University Health Sciences Center, New Orleans, USA), is necessary for production of the vector particles and contains a D116N mutation in the IN genome, preventing the functions characteristic of the IN protein [16]; plasmid pMD G [21], obtained from Dr. D. Trono (University of Lausanne, Switzerland), produces the vescicular stomatitis virus envelope glycoprotein G (VSV G).

2.2. Production of Recombinant Vectors. The human epithelium kidney 293T cell line was maintained in Dulbecco's Modified Eagles medium (Euroclone, Life Sciences Division, Pero, Milan, Italy) supplemented with $10 \%$ fetal calf serum (Euroclone, Life Sciences Division) and 100 units/mL of penicillin-streptomycin-glutamine (Gibco Invitrogen, Paisley, UK). For production of recombinant IDLV expressing HIV-Env (IDLV-JRmZ), cells were transiently transfected using the calcium phosphate-based Profection Mammalian Transfection System (Promega Corporation, Madison, WI, USA) as previously described $[16,22]$ using a total of $24 \mu \mathrm{g}$ of plasmid DNA with a ratio of $4: 3: 1$ (pTY2JRmZ:pcHelp/IN-:pMD G), thus producing the IDLV$J R m Z$ vaccine preparation. For production of control recombinant IDLV (IDLV-Empty), the pTY2-EmptymZ plasmid was used in place of pTY2-JRmZ, thus producing the IDLV-Empty vaccine preparation. After 48 hours, culture supernatants were cleared from cellular debris and passed through a $0.45 \mu \mathrm{m}$ pore size filter (Millipore Corporation, Billerica, MA, USA). Filtered supernatants were concentrated by ultracentrifugation (Beckman Coulter, Inc., Fullerton, CA, USA) for 2 hours at $27000 \mathrm{rpm}$ on a $20 \%$ sucrose gradient (Sigma Chemicals, Co., St. Louis, MO, USA). Finally, the viral pellets were resuspended in $1 \times$ PBS 
and stored at $-80^{\circ} \mathrm{C}$ for further analyses. Viral titres were normalised by the RT [23] and p24 ELISA assays (Innotest, Innogenetics, Belgium).

2.3. Mice Immunization. BALB/c mice were kept in accordance with the European Union guidelines and Italian legislation. All protocols were approved by the authors' Institutional Review Board. Four mice per group were intramuscularly immunized (i) twice with plasmid pTY2JRmZ expressing HIV-Env and mGM-CSF (DNA-JRmZ), (ii) twice with plasmid pTY2-EmptymZ expressing only mGM-CSF (DNA-Empty); (iii) once with IDLV expressing HIV-Env and mGM-CSF (IDLV-JRmZ) and (iv) once with IDLV expressing only mGM-CSF (IDLV-Empty), Mice from DNA groups were immunized intramuscularly with DNA ( $80 \mu \mathrm{g} /$ mouse) on day 0 and after 1 month were boosted with the same dose of DNA. Mice from IDLV groups received a single inoculum of $1 \times 10^{7} \mathrm{RT}$ units of IDLV formulated in $0.2 \mathrm{~mL}$ of PBS. Naïve mice were added as further control. Three months after the immunization mice were sacrificed. At sacrifice mice were first bled orbitally under metaphaneinduced anesthesia, and sera were collected and kept at $-80^{\circ} \mathrm{C}$. Single cell suspension from spleen was prepared by mechanical disruption and passage through cell streiners (BD Falcon). BM-derived cells were obtained from tibiae by syringe insertion into one end of the bone and flushing with RPMI medium.

2.4. IFN- $\gamma$ ELISPOT Assay. The IFN- $\gamma$ ELISPOT assay was performed on splenocytes and BM-derived cells by using reagents from Mabtech (Mabtech $\mathrm{AB}$ Gamla Värmdöv, Sweden) as described in [16]. The JR-9mer peptide containing the H-2 ${ }^{\mathrm{d}}$ restricted HIV-1 gp120 Envelope epitope (IGPGRAFYT) (UFPeptides s.r.l., Ferrara, Italy) and the H$2^{\mathrm{d}}$ restricted GFP-9mer peptide (HYLSTQSAL) (UFPeptides s.r.l., Ferrara, Italy) were used at $5 \mu \mathrm{g} / \mathrm{ml}$ as specific and unrelated stimuli, respectively. Concanavalin A (SIGMA, Chemical Co. St. Louis, MO, USA) was used as a positive control. Specific samples (specific peptide-treated wells) were subtracted from the values obtained in the unrelated peptidetreated wells (background) and were scored positive when were present a minimum of 50 spots per $10^{6}$ cells and a fold of 2 or higher compared to the unrelated peptide-treated samples.

2.5. Antibodies and Intracellular Staining (ICS). Splenocytes from single animals (four mice/group) were cultured with the specific JR-9mer $(5 \mu \mathrm{g} / \mathrm{mL})$ or the unrelated GFP9 mer $(5 \mu \mathrm{g} / \mathrm{mL}) \mathrm{H}-2^{\mathrm{d}}$-restricted peptides in the presence of anti-mouse CD28 $\mathrm{mAb}$ (clone 37.51) at $2 \mu \mathrm{g} / \mathrm{mL}$. PMA $(50 \mathrm{ng} / \mathrm{mL})$ in combination with Ionomicin $(2 \mu \mathrm{g} / \mathrm{mL})$ was used as positive control. After 1 hour from the stimulation, $10 \mu \mathrm{g} / \mathrm{ml}$ of Brefeldin A was added to the cultures as a protein transport inhibitor. After 6 hours of incubation, cells were stained with PercP anti-mouse CD8a, or the isotypematched $\mathrm{mAb}$. Then cells were permeabilized and stained with PE-labeled anti-mouse IL2, APC-labeled IFN $\gamma$, and PECy7-labeled TNF $\alpha$ mAbs or their isotype-matched controls in PBS- $0.5 \%$ saponin and analyzed by flow cytometry. All monoclonal antibodies were from BD Pharmingen (San Diego, CA, USA), and all chemicals were from Sigma Chemicals, Co. (St. Louis, MO, USA). Acquisition and analysis were performed using FACSCanto and FACS Diva software (BD Biosciences, USA).

2.6. In Vitro Stimulation of Effector Cells and ${ }^{51}$ Chromium Release Assay. Stimulator splenocytes from naïve BALB/c mice were pulsed for 1 hour with the Envelope-specific JR-9mer $\mathrm{H}-2^{\mathrm{d}}$-restricted peptide at $5 \mu \mathrm{g} / \mathrm{mL}$ in serum-free medium, irradiated with 3000 Rads on a ${ }^{60} \mathrm{Co}$ source, washed once, and then added to effector splenocytes derived from immunized mice, at an effector : stimulator ratio of $10: 1$. After 4 days of culture, effector cells were tested in ${ }^{51}$ Chromium release assays for the analysis of antigen-specific $\mathrm{T}$ cells, as described in [16].

2.7. Antibody Detection. Specific antibody titres against HIV-gp120 Envelope protein were measured by ELISA as previously described [16]. Briefly, ninety-six flat-bottom well microplates (Nunc GmbH \& Co. KG, Wiesbaden, Germany) were coated with $100 \mathrm{ng} /$ well of HIV-1 $1_{\text {SF162 }}$ gp120 (NIH Repository Reagents, Bethesda, MD, USA) in carbonate buffer (Sigma Chemical Co. St. Louis, MO, USA). After overnight incubation at $4^{\circ} \mathrm{C}$, wells were washed and mice sera were serially diluted and added to the plates. Goat anti mouse IgG peroxidase-conjugated secondary antibody (Sigma Chemical Co. St. Louis, MO, USA) was added to each well and incubated for an additional $90 \mathrm{~min}$ at $37^{\circ} \mathrm{C}$. Antigen-bound antibodies were revealed by the addition of ABTS solution (Roche Diagnostic S.p.a, MI, Italy). Cut-off values were established for each plate and in each run and were based on the average serum samples plus 2 standard deviations (SD) from 4 naive mice ( $\triangle$ value). Serum samples with $\triangle$ values higher than the cut-off value were considered to be positive by ELISA for HIV-Env antibodies.

2.8. Statistical Analysis. Statistical analyses were performed by nonparametric Mann-Whitney $U$ test. All $P$-values were two tailed and considered significant if less than .05. All analyses were performed using SPSS for Windows version 13.0 (SPSS Inc., Chicago Illinois US).

\section{Results and Discussion}

3.1. IDLV Is More Efficient than DNA in Inducing AntigenSpecific IFNy Producing CD8+ T Cells in Splenocytes and BM-Derived Cells. The presence and the persistence of the immune response were evaluated at 90 days from the last immunization in mice (4 mice/group) inoculated twice with plasmid DNA (DNA-JRmZ) or once with IDLV (IDLVJRmZ), both expressing codon-optimized HIV-1 $1_{\text {JR-FL }}$ gp120 Envelope and murine GM-CSF. Control arms (4 mice/group) included mice inoculated twice with plasmid DNA (DNAEmpty) or once with IDLV (IDLV-Empty), both expressing only murine GM-CSF, as well as naïve mice. As determined 


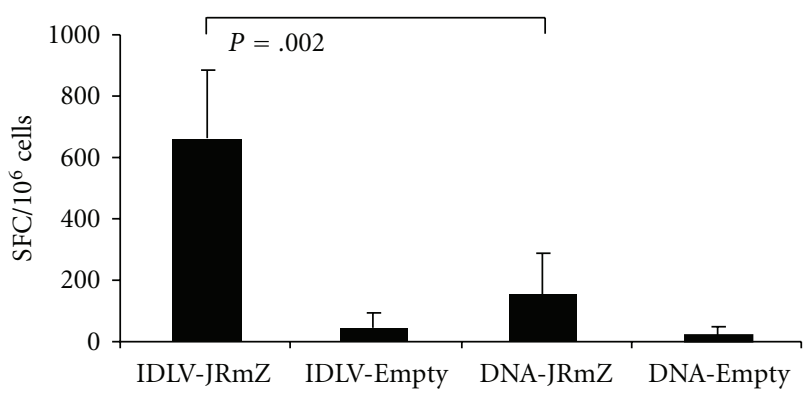

(a)

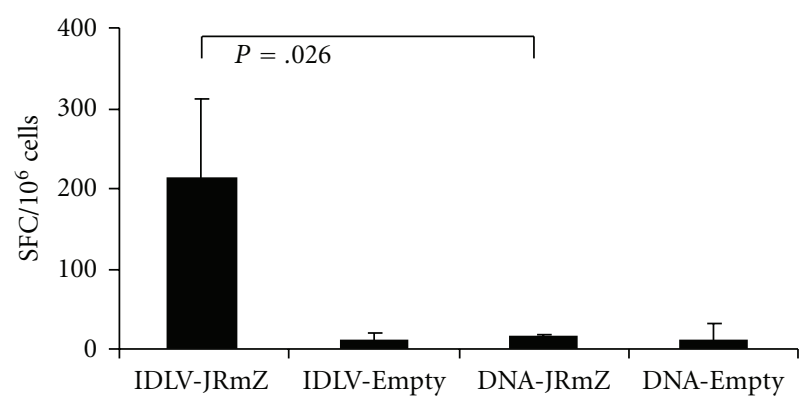

(b)

Figure 2: T cell responses measured on splenocytes (a) and BMderived cells (b) at 90 days from immunizations. Results from one representative experiment out of three independent experiments are shown. IFN- $\gamma$ ELISPOT was performed on cells stimulated overnight with either $\mathrm{H}-2^{\mathrm{d}}$ restricted specific Envelope JR-9mer peptide or $\mathrm{H}-2^{\mathrm{d}}$ restricted unrelated GFP-9mer peptide. IFN- $\gamma$ producing $\mathrm{T}$ cells are expressed as $\mathrm{SFC} / 10^{6}$ cells after background subtraction (see Section 2). The error bars indicate the standard deviation among four mice of the same group, and $P$-values are indicated for intergroup comparisons.

by IFN $\gamma$ ELISPOT on ex vivo splenocytes, IDLV-JRmZimmunized mice showed a high level of antigen specific IFN $\gamma$ producing T cells, with spot forming cells (SFC) $/ 10^{6}$ ranging from 473 to 960 , with an average value of 662 (Figure 2(a)). The number of antigen-specific IFN $\gamma$ producing T cells was lower in mice immunized twice with DNA-JRmZ (SFC/10 6 cells ranging from 35 to 345 , with an average value of 150) (Figure 2(a)). The difference between groups was statistically significant $(P<.01)$.

Recently, it has been proposed that the bone marrow $(\mathrm{BM})$ is a crucial organ for trafficking of mature T cells and contributes greatly to long-term cytotoxic memory as well as to homeostatic regulation of peripheral CD8 T cell numbers [24]. To evaluate if the vaccinations induced a memory response detectable three months after the last immunization in $\mathrm{BM}, \mathrm{IFN} \gamma$ ELISPOT was performed on BM-derived cells. IDLV-JRmZ-treated mice showed detectable levels of antigen-specific IFN $\gamma$ producing cells localized in BM (SFC/10 $0^{6}$ cells ranged from 107 to 337, with an average value of 212) (Figure 2(b)). This is particularly striking in light of the fact that only $2 \%-3 \%$ of the cells derived from BM were $\mathrm{CD} 8+$. Conversely, antigen-specific IFN $\gamma$ producing cells were not detected in BM of DNA-JRmZ-immunized mice
(Figure 2(b)). The difference between groups was statistically significant $(P<.05)$.

Overall, these results indicate that a single injection of IDLV-JRmZ is more efficient than two immunizations with DNA-JRmZ in inducing antigen-specific IFN $\gamma$ producing $\mathrm{CD} 8+\mathrm{T}$ cells. In addition, the presence of immune response in spleen and BM at three months from the single immunization indicates that IDLV is able to induce a long-lasting immunity.

3.2. IDLV Immunization Induces Functional Cytotoxic T Lymphocytes (CTLs). To analyze the effective ability of antigenspecific CD8+ T cells induced by the vaccines in killing target cells, a chromium release assay was performed. This was deemed necessary since production of IFN $\gamma$ by CD8 $+\mathrm{T}$ cells does not directly imply their ability to kill target cells, as it has been already demonstrated for instance in the case of HIVinfected patients, where the ability to produce cytokines was not associated with the cytolytic function [25].

The presence of CTL was investigated on splenocytes derived from immunized mice, stimulated in vitro with irradiated naïve splenocytes pulsed with the specific Envelope JR-9mer peptide. Specific lysis of target cells was evident in mice immunized once with IDLV-JRmZ (up to $30 \%$ of specific lysis at $\mathrm{E}: \mathrm{T}$ ratio of $40: 1$ ), whereas splenocytes from mice immunized twice with DNA-JRmZ did not show CTL activity at any E : T ratio tested (Figure 3(a)). No specific responses were detected in the mice immunized with DNA-Empty, and IDLV-Empty and in naïve mice, used as negative controls (Figure 3(a)).

These data clearly indicated that only the immunization with IDLV-JRmZ was able to induce antigen-specific CD8+ $\mathrm{T}$ cells competent for both cytokine production and cytolytic effector function.

\subsection{IDLV Immunization Induces Antigen-Specific Antibody} Response. An efficient antibody response was not expected upon immunization with IDLV-JRmZ, due to the reported low protein expression from the non-integrated viral E-DNA [14]. Indeed, mice immunized with IDLV-JRmZ displayed low but detectable anti-Env IgG titers (geometric median titer 400) whereas mice immunized with DNA-JRmZ did not generate any antibody response (Figure 3(b)). Results were comparable to those obtained in a previous experiment using the same IDLV [16]. The presence of a specific antibody response in the case of IDLV is attractive, considering a possible prime-boost vaccine protocol, using IDLV as priming and the corresponding protein for boosting humoral response.

\subsection{IDLV Immunization Induces Polyfunctional CD8+ $T$} Cells. Several authors have recently confirmed the efficacy of IDLV vaccination in animal models $[17-20,26]$. Due to its safety profile and immunization efficiency, there is, therefore, an increasing interest in the use of this vector for vaccine purposes in different disease models, including viral infections and tumors [27].

To further characterize the CD8+ T cell response, we carried out a more detailed analysis of the quality of immune 


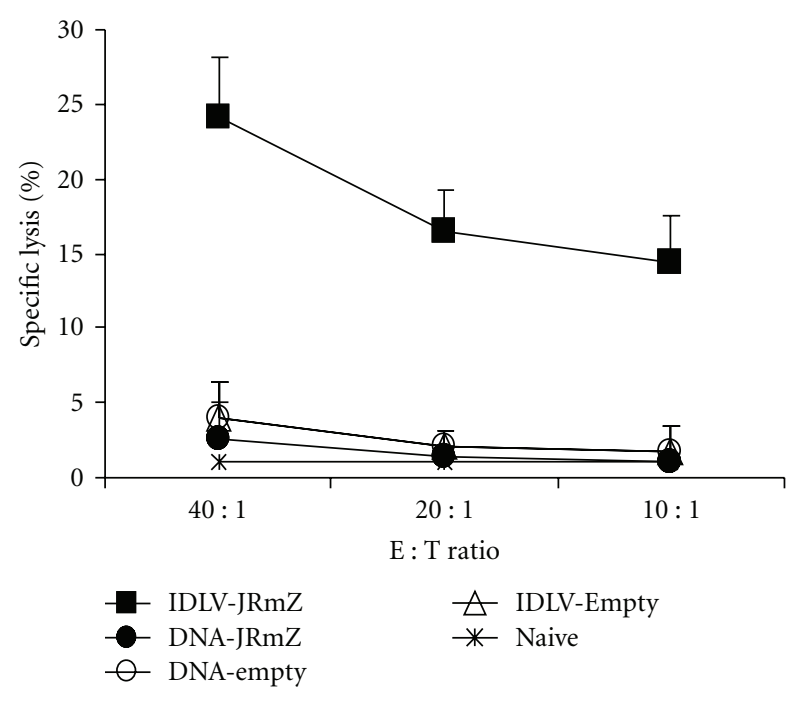

(a)

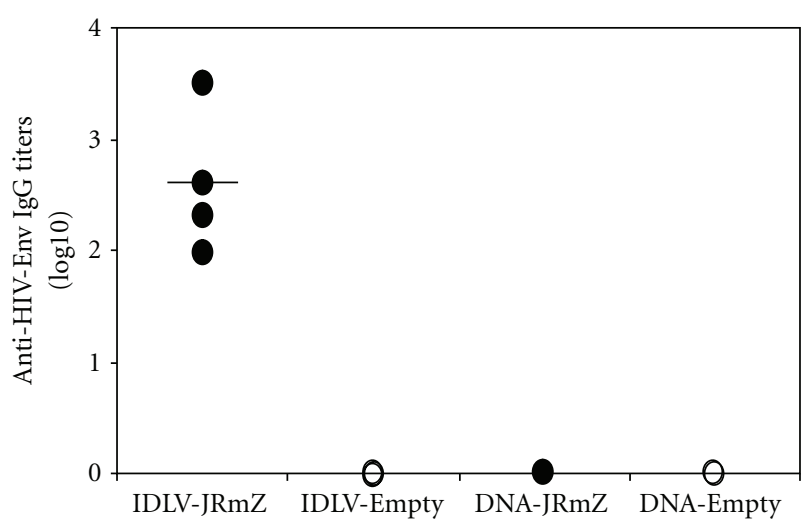

(b)

FIgUre 3: (a) Anti-Env specific CTL activity in mice immunized with IDLV-JRmZ, IDLV-Empty, DNA-JRmZ, and DNA-Empty or in naive mice (four mice/group). Results from one representative experiment out of three independent experiments are shown. ${ }^{51} \mathrm{Cr}$-release assay was performed after 4 days in vitro culture, as described in Section 2. The percentage of specific lysis is shown at three different $\mathrm{E}:$ T ratios: $40: 1,20: 1$, and $10: 1$. (b) Anti-HIVEnv IgG antibodies measured by ELISA in sera of mice at 90 days after immunization. Sera samples from the immunized mice were analyzed separately. Line represents the geometric median value in the IDLV-JRmZ group.

response induced by IDLV immunization. In particular, an intracellular staining (ICS) for IFN $\gamma, \mathrm{TNF} \alpha$, and IL2 was performed in splenocytes of mice immunized with IDLV-JRmZ and DNA-JRmZ and control mice. As shown in Figure 4(a), CD8+ $\mathrm{T}$ splenocytes from both IDLV-JRmZ- and DNAJRmZ-immunized animals produced all three cytokines, when cultured in vitro in the presence of the Envelopespecific peptide. Importantly, IDLV-JRmZ-immunized mice showed a statistically significant higher percentage of CD8+ T cells producing IFN $\gamma$, TNF $\alpha$, or IL2 when compared to DNA-JRmZ-vaccinated mice $(P<.05)$. Splenocytes from naïve mice or from mice immunized with IDLV-Empty and DNA-Empty did not show any significant production of cytokines.

To evaluate the presence of polyfunctional antigenspecific CD8+ T cells, IFN $\gamma$ producing CD8+ T cells were gated and evaluated for production of $\mathrm{TNF} \alpha$ and IL2. In Figure 4(b) a representative analysis shows that the majority of the IFN $\gamma$-producing CD8+ T cells from the IDLV-JRmZ and DNA-JRmZ-immunized mice also produce TNF $\alpha$ and IL2 (86\% and $75 \%$, respectively). These results indicate that while both vaccinations qualitatively induced similar CD8+ $\mathrm{T}$ cell responses, immunization with IDLV induced a higher number of polyfunctional antigen-specific T cells.

It has been suggested that the presence of such polyfunctional cells correlates with a better prognosis in chronically infected patient with CMV and EBV and in long-term non progressor HIV-1-infected patients [28]. Therefore, the use of IDLV-based vaccines, capable of inducing high levels of polyfunctional CD8 $+\mathrm{T}$ cells, after a single immunization represents a very attractive and desirable vaccine strategy.

\section{Conclusions}

Usually, the immune response induced by DNA injection is weak. To circumvent this limitation in our study we used a single intramuscular injection of IDLV-delivered Envelope sequence in the mouse model which performed better than two immunizations with naked DNA plasmid delivering the same antigen. The mGM-CSF coding sequence was included in both immunization protocols in the effort to improve immune response. Nevertheless, two immunizations with DNA were not sufficient to induce an immune response comparable to that induced by a single immunization with IDLV expressing the same antigen. The difference in the ability to induce immune response could be partly explained by considering the advantage of the vector, in terms of uptake and stability in vivo, compared with naked DNA. The delivery of DNA through electroporation (EP) might overcome these limitations, even if safety-related issues of $\mathrm{EP}$, in the case of administration of vaccines to humans, need to be better investigated [29]. However, the aim of our study was to provide evidence of the potency of IDLV as a vaccine and to characterize the CD8+ $\mathrm{T}$ cell response induced by this novel, safe, and promising vector for genetic immunization.

The efficiency of IDLV observed in our and in other models [27], in terms of quantity, persistence, and quality of CD8+ $\mathrm{T}$ cell response, could be reasonably considered an excellent beginning for future exploitation of this vector for developing vaccine strategies aimed at inducing CD8+ T cell responses. The possibility to use IDLV in heterologous prime-boost protocols as well as in mucosal vaccine, in order to improve immune response at both systemic and mucosal sites, should be further investigated. Finally, to have the proof of concept that this vector could represent a novel and effective delivery system for vaccine strategies in humans, experiments in the nonhuman primate model of AIDS should be performed by evaluating the strength of the 


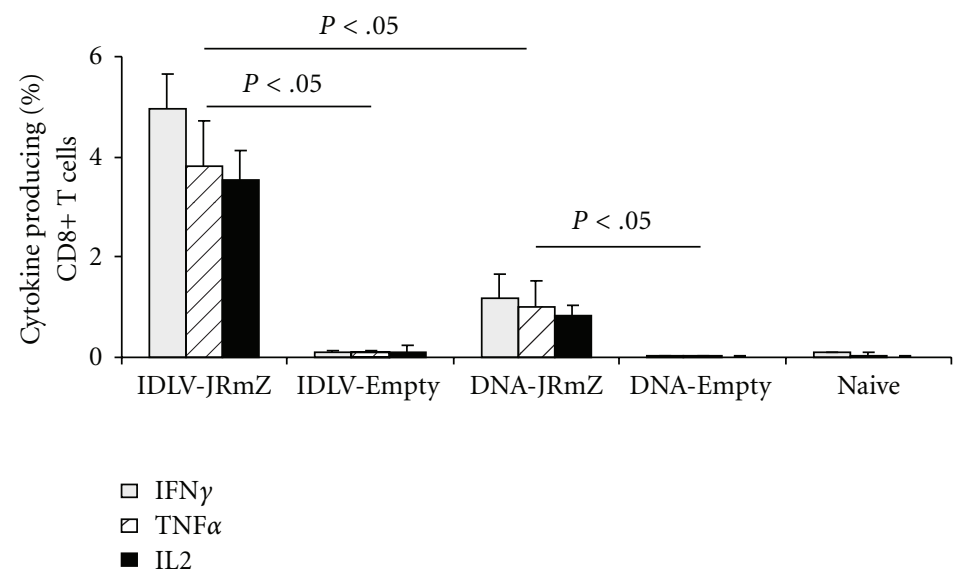

(a)

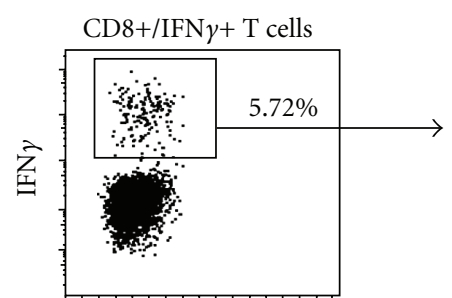

FSC-A

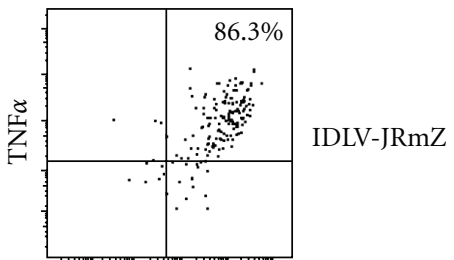

IL2

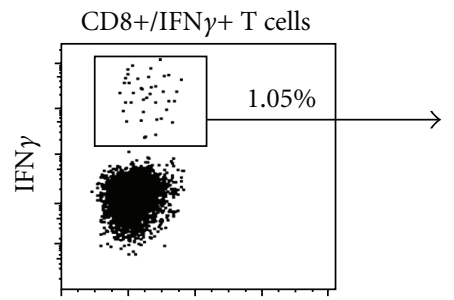

FSC-A

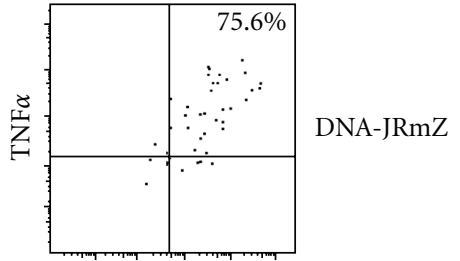

IL2

(b)

FIGURE 4: Analysis of cytokine production by intracellular staining (ICS). Results from one representative experiment out of three independent experiments are shown. (a) Splenocytes from mice immunized with IDLV-JRmZ, DNA-JRmZ, IDLV-Empty, and DNA-Empty or from naïve mice were cultured in vitro with Envelope-specific JR-9mer peptide and then stained for IFN $\gamma$, TNF $\alpha$, and IL2. Error bars indicate the standard deviation among four mice of the same group. Data are expressed as percentage of single cytokine-producing $\mathrm{T}$ cells by gating the CD8+ T cell population. (b) IDLV-JRmZ vaccination induced high frequency of polyfunctional antigen-specific CD8+ T cells able to simultaneously produce IFN $\gamma$, IL2, and TNF $\alpha$. A representative experiment is shown. The analysis was performed on CD8+ T cells from the mice immunized with IDLV-JRmZ (upper panels) or DNA-JRmZ (lower panels). CD8+/IFN $\gamma$-producing cells were gated and analyzed for the production of both TNF $\alpha$ and IL2. Within the dot plots the percentages of single (IFN $\gamma$ ) and double (TNF $\alpha$ and IL2) cytokine-producing CD8+ T cells are indicated. FSC: forward scatter.

immune response induced in terms of both frequency and quality of viral-specific $\mathrm{T}$ cells and the ability in controlling the viral challenge.

\section{Acknowledgments}

The following reagent was obtained through the AIDS Research and Reference Reagent Program, Division of AIDS, NIAID, NIH: HIV-1 $1_{\text {SF162 }}$ gp120. This work was funded by grants from the Italian AIDS National Program. The authors declare no conflict of interest.

\section{References}

[1] A. J. McMichael, "Principles of immunology," in Oxford Textbook of Medicine, D. A. Warrell, T. M. Cox, J. D. Firth, and E. J. Benz, Eds., pp. 131-144, Oxford University Press, Oxford, UK, 4th edition, 2003.

[2] X. Jin, D. E. Bauer, S. E. Tuttleton, et al., "Dramatic rise in plasma viremia after $\mathrm{CD}^{+} \mathrm{T}$ cell depletion in simian immunodeficiency virus-infected macaques," The Journal of Experimental Medicine, vol. 189, no. 6, pp. 991-998, 1999.

[3] J. E. Schmitz, M. J. Kuroda, S. Santra, et al., "Control of viremia in simian immunodeficiency virus infection by $\mathrm{CD}^{+}$ lymphocytes," Science, vol. 283, no. 5403, pp. 857-860, 1999. 
[4] B. T. Korber, N. L. Letvin, and B. F. Haynes, "T-cell vaccine strategies for human immunodeficiency virus, the virus with a thousand faces," The Journal of Virology, vol. 83, no. 17, pp. 8300-8314, 2009.

[5] R. A. Koup, M. Roederer, L. Lamoreaux, et al., "Priming immunization with DNA augments immunogenicity of recombinant adenoviral vectors for both HIV-1 specific antibody and T-cell responses," PLoS ONE, vol. 5, no. 2, article e9015, 2010.

[6] Y. He and L. D. Falo Jr., "Lentivirus as a potent and mechanistically distinct vector for genetic immunization," Current Opinion in Molecular Therapeutics, vol. 9, no. 5, pp. 439-446, 2007.

[7] N. Chinnasamy, D. Chinnasamy, J. F. Toso, et al., "Efficient gene transfer to human peripheral blood monocyte-derived dendritic cells using human immunodeficiency virus type 1based lentiviral vectors," Human Gene Therapy, vol. 11, no. 13, pp. 1901-1909, 2000.

[8] J. Dyall, J.-B. Latouche, S. Schnell, and M. Sadelain, "Lentivirus-transduced human monocyte-derived dendritic cells efficiently stimulate antigen-specific cytotoxic T lymphocytes," Blood, vol. 97, no. 1, pp. 114-121, 2001.

[9] M. C. Iglesias, K. Mollier, A.-S. Beignon, et al., "Lentiviral vectors encoding HIV-1 polyepitopes induce broad CTL responses in vivo," Molecular Therapy, vol. 15, no. 6, pp. 1203 1210, 2007.

[10] V. Buffa, D. R. M. Negri, P. Leone, et al., "A single administration of lentiviral vectors expressing either full-length human immunodeficiency virus 1 (HIV-1)HXB2 Rev/ Env or codonoptimized HIV-1JR-FL gp 120 generates durable immune responses in mice," The Journal of General Virology, vol. 87, no. 6, pp. 1625-1634, 2006.

[11] V. Buffa, D. R. M. Negri, P. Leone, et al., "Evaluation of a selfinactivating lentiviral vector expressing simian immunodeficiency virus gag for induction of specific immune responses in vitro and in vivo," Viral Immunology, vol. 19, no. 4, pp. 690 701, 2006.

[12] A.-S. Beignon, K. Mollier, C. Liard, et al., "A lentiviral vectorbased prime/boost vaccination against AIDS: a pilot study shows protection against Simian immunodeficiency virus SIVmac251 challenge in macaques," The Journal of Virology, vol. 83, no. 21, pp. 10963-10974, 2009.

[13] J. Vargas Jr., G. L. Gusella, V. Najfeld, M. E. Klotman, and A. Cara, "Novel integrase-defective lentiviral episomal vectors for gene transfer," Human Gene Therapy, vol. 15, no. 4, pp. 361372, 2004.

[14] A. Cara and M. E. Klotman, "Retroviral E-DNA: persistence and gene expression in nondividing immune cells," Journal of Leukocyte Biology, vol. 80, no. 5, pp. 1013-1017, 2006.

[15] Y. Zheng, I. Ourmanov, and V. M. Hirsch, "Persistent transcription of a nonintegrating mutant of simian immunodeficiency virus in rhesus macrophages," Virology, vol. 372, no. 2, pp. 291-299, 2008.

[16] D. R. M. Negri, Z. Michelini, S. Baroncelli, et al., "Successful immunization with a single injection of non-integrating lentiviral vector," Molecular Therapy, vol. 15, no. 9, pp. 17161723, 2007.

[17] F. Coutant, M.-P. Frenkiel, P. Despres, and P. Charneau, "Protective antiviral immunity conferred by a nonintegrative lentiviral vector-based vaccine," PLOS ONE, vol. 3, no. 12, article e3973, 2008.

[18] K. Karwacz, S. Mukherjee, L. Apolonia, et al., "Nonintegrating lentivector vaccines stimulate prolonged T-cell and antibody responses and are effective in tumor therapy," The Journal of Virology, vol. 83, no. 7, pp. 3094-3103, 2009.

[19] B. Hu, H. Yang, B. Dai, A. Tai, and P. Wang, "Nonintegrating lentiviral vectors can effectively deliver ovalbumin antigen for induction of antitumor immunity," Human Gene Therapy, vol. 20, no. 12, pp. 1652-1664, 2009.

[20] Z. Michelini, D. R. M. Negri, S. Baroncelli, et al., "Development and use of SIV-based Integrase defective lentiviral vector for immunization," Vaccine, vol. 27, no. 34, pp. 4622-4629, 2009.

[21] L. Naldini, U. Blomer, P. Gallay, et al., "In vivo gene delivery and stable transduction of nondividing cells by a lentiviral vector," Science, vol. 272, no. 5259, pp. 263-267, 1996.

[22] R. Bona, M. Andreotti, V. Buffa, et al., "Development of a human immunodeficiency virus vector-based, single-cycle assay for evaluation of anti-integrase compounds," Antimicrobial Agents and Chemotherapy, vol. 50, no. 10, pp. 3407-3417, 2006.

[23] R. Weiss, “ The search for human RNA tumor viruses," in RNA Tumor Viruses, R. Weiss, N. Teich, H. Varmus, and J. Coffin, Eds., pp. 1205-1218, Cold Spring Harbor Laboratory Press, Cold Spring Harbor, NY, USA, 2nd edition, 1982.

[24] F. Di Rosa and R. Pabst, "The bone marrow: a nest for migratory memory T cells," Trends in Immunology, vol. 26, no. 7, pp. 360-366, 2005.

[25] V. Appay, D. F. Nixon, S. M. Donahoe, et al., "HIV-specific $\mathrm{CD}^{+} \mathrm{T}$ cells produce antiviral cytokines but are impaired in cytolytic function," The Journal of Experimental Medicine, vol. 192, no. 1, pp. 63-75, 2000.

[26] M. B. Banasik and P. B. McCray Jr., "Integrase-defective lentiviral vectors: progress and applications," Gene Therapy, vol. 17, no. 2, pp. 150-157, 2010.

[27] K. Wanisch and R. J. Yáñez-Muñoz, "Integration-deficient lentiviral vectors: a slow coming of age," Molecular Therapy, vol. 17, no. 8, pp. 1316-1332, 2009.

[28] V. Appay, P. R. Dunbar, M. Callan, et al., "Memory CD8 ${ }^{+} \mathrm{T}$ cells vary in differentiation phenotype in different persistent virus infections," Nature Medicine, vol. 8, no. 4, pp. 379-385, 2002.

[29] A.-K. Roos, F. Eriksson, J. A. Timmons, et al., "Skin electroporation: effects on transgene expression, DNA persistence and local tissue environment," PLOS ONE, vol. 4, no. 9, article e7226, 2009. 


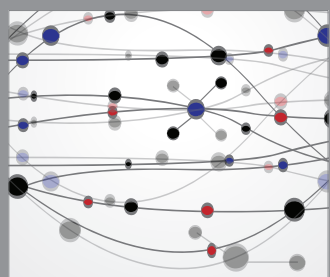

The Scientific World Journal
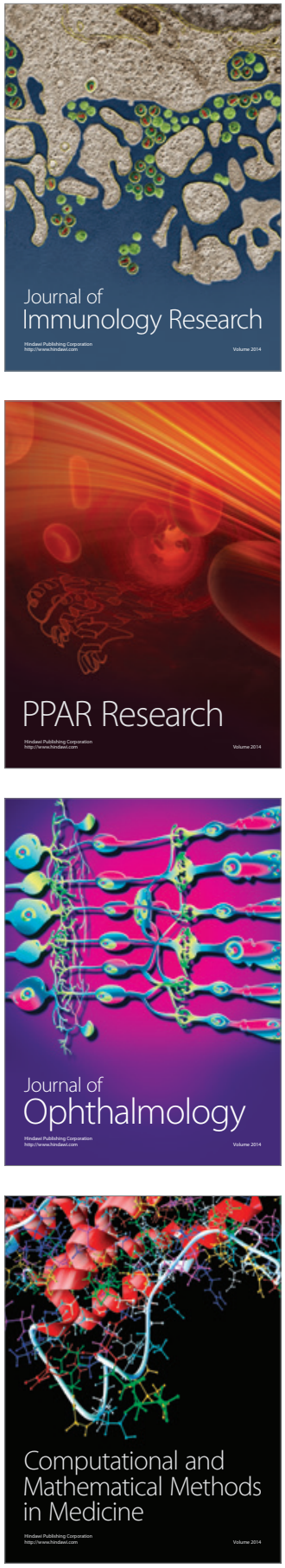

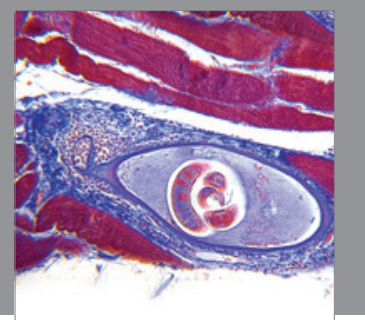

Gastroenterology

Research and Practice
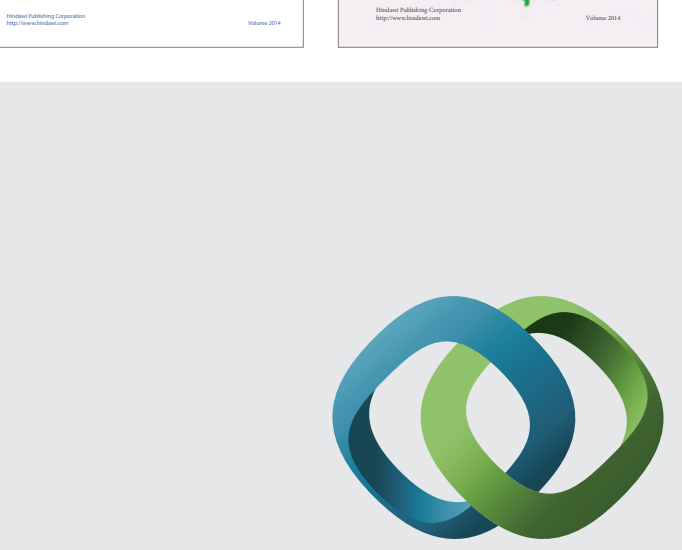

\section{Hindawi}

Submit your manuscripts at

http://www.hindawi.com
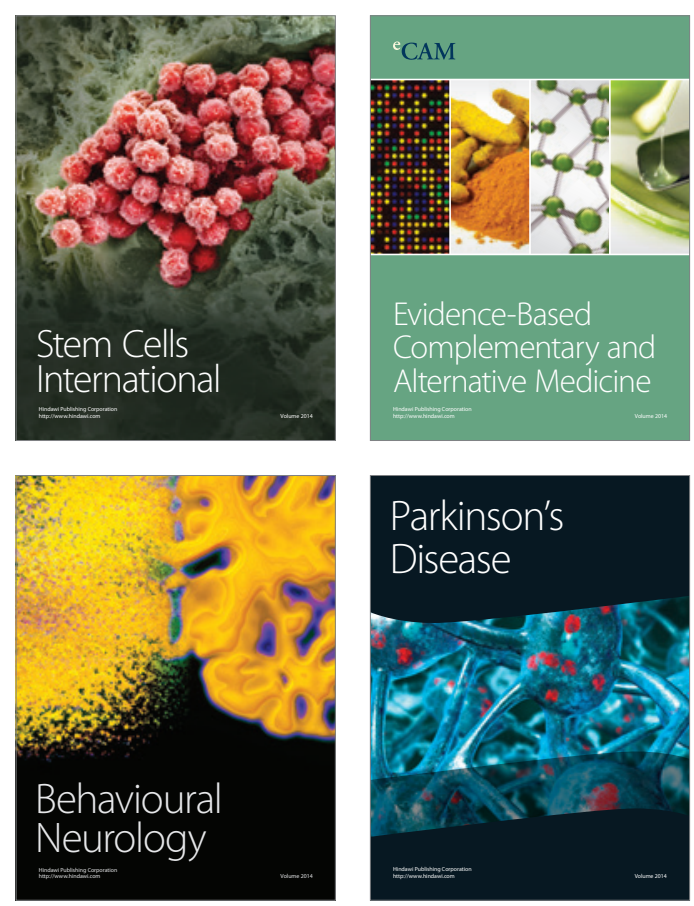

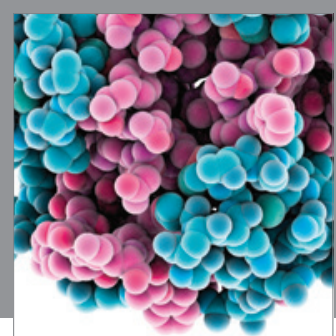

Journal of
Diabetes Research

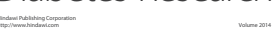

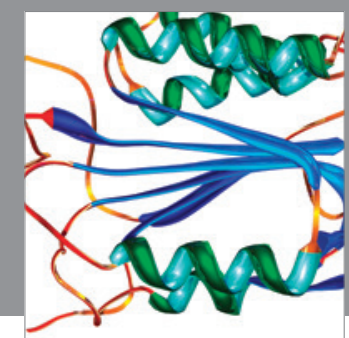

Disease Markers
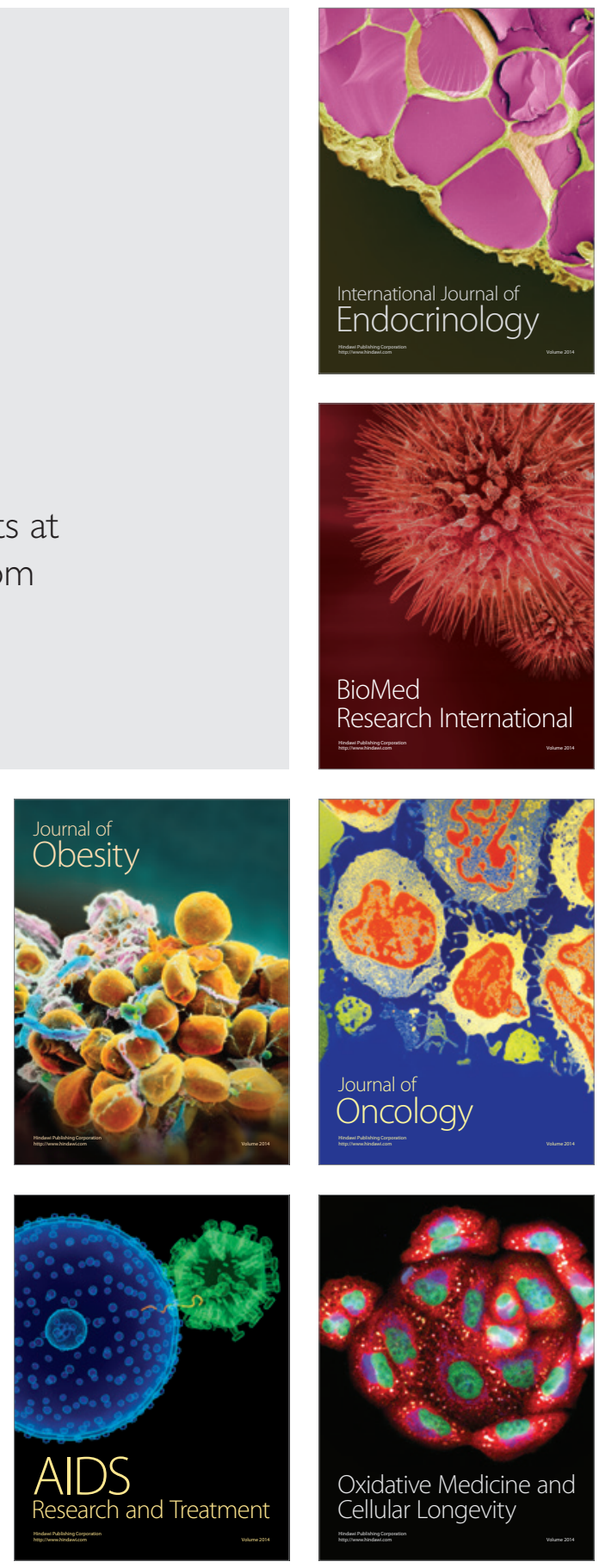